\title{
High country development: integrating clovers, soils and merinos
}

\author{
WILLIE and SUSAN MACDONALD \\ Middlehurst Station, Private Bag, Blenheim
}

\section{Introduction}

Middlehurst is a 16,723 ha high country property in the Awatere Valley, a close neighbour to Molesworth and some $114 \mathrm{~km}$ from Blenheim. In 1998 we purchased 5303 ha of freehold and a pastoral lease of 11,420 ha with 28 years to run on its current lease, running 7520 sheep stock units (su) and 3400 cattle su. Currently we are running 15,632 total su, down $2200 \mathrm{su}$ due to destocking our other properties because of the drought (Table 1). The altitude range is $600-2400 \mathrm{~m}$ a.s.1 with the homestead and major buildings at $850 \mathrm{~m}$ a.s.l. Altitude is not a major limiting factor but rainfall is, with a long term average of $550 \mathrm{~mm}$, a range $364-1031 \mathrm{~mm}$, and an erratic seasonal pattern. The soils are dominantly Middlehurst brown granular silt and clay loams derived from basalt and andesite parent material of medium natural fertility: $\mathrm{pH} 5.8-6.0$ and Olsen P of 15-20. Currently the land use is: 4920 ha oversown and topdressed, 21 ha lucerne, 12 ha winter crop, 5000 ha native grazing, 6800 ha no grazing. In 2001, we purchased a 550 ha finishing block at Cheviot to complement the development and management of Middlehurst and very recently a block at Havelock.

\section{Philosophies}

We arrived on Middlehurst as the rabbits left - courtesy of RCD, so were presented with a golden opportunity to develop. We were very aware of the fragile environment we came to, and were determined to implement a simple, cost effective and productive farming operation. A key factor is an all grass wintering system and the role of the Cheviot farm in finishing young stock. Furthermore, in the interests of reducing risk and encouraging stability, we have given emphasis to developing long term relationships with product supply chain partners. We are producers that are market led. We look to maintain and increase sustainable, long term customised production based on breeding plain-bodied merinos.

Table 1 Stock numbers and estimates of income and expenditure for 1998 - 2007

\begin{tabular}{|c|c|c|c|c|c|c|c|c|c|c|}
\hline & Apr 98 & $98 / 99$ & $99 / 00$ & 00/01 & 01/02 & $02 / 03$ & 03/04 & $04 / 05$ & 05/06 & $06 / 07$ \\
\hline \multicolumn{11}{|l|}{ Stock } \\
\hline Ewes & 1900 & 4000 & 4400 & 4500 & 4850 & 5080 & 5005 & 5284 & 4800 & 5095 \\
\hline E Hgts & 750 & 1250 & 2000 & 1850 & 1900 & 2064 & 2300 & 2300 & 2400 & 2158 \\
\hline Rams & 20 & 50 & 50 & 60 & 100 & 106 & 105 & 100 & 80 & 75 \\
\hline WHgts & 750 & 1250 & 2000 & 1850 & 2026 & 2065 & 2310 & 2393 & 2490 & 2258 \\
\hline Wths & 1800 & 500 & 0 & 0 & 0 & 50 & 0 & 0 & 0 & 0 \\
\hline Total & 5220 & 7050 & 8450 & 8260 & 8876 & 9365 & 9720 & 10077 & 9770 & 9587 \\
\hline Sheep SU & 4451 & 6515 & 7840 & 7693 & 8286 & 8710 & 8316 & 8649 & 8247 & 8247 \\
\hline Cows & 105 & 165 & 165 & 210 & 346 & 342 & 388 & 346 & 418 & 444 \\
\hline $\mathrm{Hfs}$ & 40 & 98 & 165 & 180 & 284 & 368 & 369 & 284 & 448 & 455 \\
\hline Bulls & 20 & 9 & 7 & 9 & 12 & 13 & 21 & 12 & 15 & 16 \\
\hline Steers & 80 & 147 & 158 & 185 & 352 & 339 & 368 & 352 & 439 & 577 \\
\hline Total & 245 & 419 & 495 & 584 & 994 & 1062 & 1146 & 994 & 1320 & 1492 \\
\hline Cattle SU & 1240 & 2108 & 2511 & 2965 & 5004 & 5421 & 5664 & 4956 & 6508 & 7385 \\
\hline Total SU & 5691 & 8623 & 10351 & 10658 & 13290 & 14131 & 13980 & 13605 & 14755 & 15632 \\
\hline Kg Wool & & 24000 & 32258 & 31238 & 34578 & 45401 & 45595 & 52523 & 49421 & 45967 \\
\hline $\mathrm{Kg}$ wool/su & & 5.38 & 4.95 & 3.98 & 4.49 & 5.21 & 5.48 & 6.07 & 5.99 & 5.57 \\
\hline \multicolumn{11}{|c|}{ Income and Expenditure Indicators } \\
\hline $\mathrm{GFI} 1 / \mathrm{su}$ & & -30.25 & 33.49 & 51.32 & 33.24 & 59.16 & 54.46 & 69.55 & 67.24 & 56.18 \\
\hline Wages/su & & 1.25 & 3.02 & 5.39 & 6.23 & 8.90 & 10.94 & 11.07 & 6.78 & 6.55 \\
\hline An H/su & & 2.75 & 3.06 & 5.46 & 4.04 & 4.04 & 4.82 & 2.27 & 3.30 & 3.74 \\
\hline Seed/su & & 2.86 & 1.82 & 2.05 & 0.08 & 2.20 & 0.84 & 1.28 & 0.75 & 0.99 \\
\hline Fert/su & & 9.70 & 2.81 & 5.48 & 6.15 & 6.66 & 6.29 & 7.31 & 5.00 & 7.52 \\
\hline Shear/su & & 4.79 & 2.97 & 3.80 & 4.08 & 3.64 & 3.52 & 4.57 & 4.30 & 3.94 \\
\hline Weed \& Pest & & 2.41 & 4.72 & 3.87 & 4.59 & 4.58 & 2.02 & 3.99 & 2.09 & 3.98 \\
\hline$R \& M^{1}$ & & 4.51 & 4.06 & 15.17 & 2.68 & 7.66 & 6.90 & 10.98 & 0.74 & 5.31 \\
\hline $\mathrm{FWE}^{1 / \mathrm{su}}$ & & 44.61 & 27.83 & 51.03 & 33.87 & 45.55 & 52.48 & 54.68 & 37.00 & 43.76 \\
\hline Surplus/su & & -74.86 & 5.66 & 0.30 & -0.63 & 13.62 & 1.98 & 14.87 & 30.24 & 12.42 \\
\hline
\end{tabular}

GFI is gross farm income; R\&M is repairs \& maintenance; FWE is farm working expenses 


\section{Development}

Our development strategy was built around recognising Middlehurst's strengths - soils, stock health and scope, and using these as a base on which to apply science and genetics. In our first year we sold the complete 1800 head wether flock, allowing us to spell country previously set stocked for 90 years and at the same time increase ewe numbers by 2000 .

The physical development programme started on potential lambing blocks and consisted of fencing, fertiliser and seed. The blocks where the native Hieraceum had invaded were oversown in mid-late August to take advantage of frost lift with $3 \mathrm{~kg}$ Tahora white clover, 2$3 \mathrm{~kg}$ Leura sub clover, $1 / 2 \mathrm{~kg}$ Montgomery red clover, 2 kg Tekapo cocksfoot with $100 \mathrm{~kg}$ Sulphur Super 30. In some sites Caucasian clover has also been used. The seed is always sown separately through a Ventura seeder fitted to the aircraft to get a better distribution. The initial application was followed by $100 \mathrm{~kg} / \mathrm{ha}$ of Maxi Sulphur Super $(50 \%)$ in year 2 and then going into a 3 year cycle of $100 \mathrm{~kg} / \mathrm{ha}$ of Maxi Sulphur Super. Annual fertiliser maintenance has consistently been 200 tonnes.

The key to pasture development success was to shut the gate for the first two spring/summers to allow for reseeding. Easy to say but it takes courage to resist the temptation to graze the lush green clover dominant sward. While this destocking policy had little direct production cost as the land was unproductive prior to development, it had significant benefit in clover reseeding. Initially the clovers dominated the Hieraceum, and then the cocksfoot and other grasses came through. Generally the Hieraceum is still there underneath and shows up again in dry years, or from excessive grazing pressure such as rabbits. It is our concern that without fertiliser, particularly sulphur, it will not take long to revert.

By 2002, some 1390 ha had been oversown and topdressed with the standard package at altitudes of up to $1600 \mathrm{~m}$ a.s.1 lifting carrying capacity to 14,131 total su (Table 1). In 2005 and 2006 a further 580 ha was given the standard development package, but no lift in stocking resulted because of climatic constraints. When development started, the initial cost of fertiliser and seed was $\$ 60 /$ ha or about $\$ 145 /$ ha including fencing etc. for a 2.5 su increase. A major review of the fertiliser programme is currently underway with extensive soil tests being done at present plus alternative products being researched. Fertiliser will now be close to $\$ 800 /$ tonne (July 2008 prices) on the ground, or $\$ 11 /$ su.

\section{Subdivision}

The original blocks ranged from 660 to 1500 ha. Our aim has been to get block size in the range of 200-400 ha for better pasture management and also for more suitable mob sizes for lambing. Ewes are lambed in October at around 1.5 to 2 ewes/ha plus up to 10 cows per 100 ewes are stocked during the calving/lambing period. Fencing consists of 7 wire permanent post and waratah construction. In all some $23 \mathrm{~km}$ of new fencing was completed in the first 5 years.

\section{Weed and Pest Control}

Alongside the development programme, an ongoing containment and eradication programme of broom control has been in place at an annual cost of some $\$ 40,000$. We have tried to work methodically from the top of hill faces down to the river or valley floor, with scattered and outlying patches taking priority. A Jet Ranger helicopter is used for the main blanket spraying, being careful not to get too far ahead to compromise our ability to complete follow up work. A Robinson 22 is also used for isolated bushes and spot spraying which is combined with ground spraying and application of prills when mustering. Briar has increased a lot over the past 3 years and we will start on a spraying programme this year if the season allows. At least briar is a feed source for the stock in early winter with its berries!

The reappearance of the rabbit has forced a renewed control policy. Last year, 1600 ha was poisoned with pindone pellets, with 800 ha due to be done this year. Use of pindone pellets enables stock to return to the poisoned block quicker as the pellets break down quickly with minimal moisture. In contrast 1080 pellets are still highly toxic unless significant rain has broken them down completely. This can be months in our environment.

\section{Cheviot Block}

The purchase of the Cheviot block in 2001 further modified the management by allowing control further down the supply chain and thereby movement from a weak seller position. All lambs are retained and after shearing in September all surplus hoggets are shifted to Cheviot for finishing and slaughter on a winter lamb contract by November. Yearling cattle also go to Cheviot as required, as do cull ewes which do a further one or two lambings before going to the works. Until this year, these ewes have been mated to a terminal sire but we have now reverted to using merino rams. This winter Cheviot will winter 750 ewes, 800 hgts, 450 weaner calves and $90 \mathrm{R} 2 \mathrm{yr}$ in-calf heifers.

\section{Animal Genetics}

The original stock purchased were of good size, constitution and fertility but too strong for modern market requirements. Using imported genetics we set about changing both fleece weight and micron count. We purchased Soft Rolling Skin rams (SRS) from Australia and used Cervical Artificial Insemination (CAI) over some 3500 ewes every year, on a natural 17-day cycle 
for a number of years. This has allowed us to breed rams for our own use as well as for sale. The policy has allowed us to develop dual purpose Merino ewes that cut $6.5-6.8 \mathrm{~kg} / \mathrm{hd}$ of 20 micron wool as against the 5.4 $\mathrm{kg} / \mathrm{hd}$ of 23 micron wool they produced at takeover. The plain-bodied Merino we produce is proof that you can have a highly productive sheep both in terms of meat and wool that does not require mulesing. Attention to detail, not only in the genetics programme, but also in shed handling and general animal husbandry has led to ZQue accreditation and premium price contracts with Smartwool and Icebreaker facilitated through NZ Merino Company. We have clear specifications to meet which we know we can achieve and we are paid for our efforts which removes a major source of financial risk. A bonus from our breeding programme this year was the sale of 6 rams and 10 ewes to a French farmer which we personally delivered to his doorstep.

\section{Meat Production}

In line with our basic philosophy in regard to wool production we have devoted significant time and effort into meat production as well. Our lamb meat production, some $40,530 \mathrm{~kg}$ in the 2007/8 season, has given us close relationships with Matukituki Ventures Ltd. Being able to shift our merino lambs from Middlehurst to Cheviot in late September after they are shorn has huge advantages. When the lambs leave Middlehurst it is still late winter but they arrive at Cheviot when spring is well under way. This also allows us a lighter stocking rate for ewes at lambing time. The lambs are very easy and cheap to winter at home and with careful management adjust well to the feed change at Cheviot. A month after arrival they are weighed up into three weight ranges for ease of management and killed progressively as they reach the appropriate weight.

On the cattle side, we have changed from pure Angus to composites, thereby increasing hybrid vigour. This season's beef output will total 111,000 kg. Our most recent move has been to purchase 150 ha of former dairy land at Havelock which will shift the beef focus from Cheviot and give us the potential in 2008/09 to produce some $187,000 \mathrm{~kg}$ of beef.

Under our new policy, replacement heifer calves will head to Cheviot, go to the bull there as yearlings, possibly calving there before returning to Middlehurst. Some steer calves may still be wintered down there too, season dependent. We are still in the early stages of working the new beef block in with the rest of our systems. We will then have the added advantage of being able to wean early in mid April as opposed to mid-June and therefore get some condition back on the cows before winter. With no young cattle remaining on Middlehurst after weaning we will look at lifting our cow or ewe numbers when and if seasons allow.

\section{Potential Development}

We have definitely picked the eyes out of the development opportunities but there is more that can be done. Under current costings for fertiliser, seed and fencing (Table 1), this does not look likely in the short term. In the hill country, we still cannot grow anything of high nutritional value for late winter, early spring - the last 6 weeks of pregnancy. This is an area we need to work on. Current (2008) development costs including fencing are about $\$ 145 /$ ha or $/ 2.5 \mathrm{su}$. If the seasons continue as they have been with poor springs and autumns along with poor product returns, further changes may have to be implemented in terms of management and objectives. Maybe more crops, more baleage/hay, irrigation. Personally we don't like the idea of any of those!

\section{Conclusion}

A decade ago we purchased a high country property challenging us to seize a development opportunity created by the demise of the rabbit and to establish a simple, cost effective, productive farming system in a fragile environment. By applying good science and technology, and using the resources of complementary land we have undoubtedly improved productivity, and by using marketing contracts ameliorated some sources of risk. The last three seasons have however reminded us that two potential risks remain untamed, namely dry years and the return of the rabbit. The latter looks likely to impose a yearly rental of at least $\$ 5 /$ ha or $\$ 5 /$ su. Whether our farming practices remain sustainable depends to a significant extent on the ability of the developed land to respond to better rainfall levels, depressed rabbit levels and the recovery powers of the clover seed bank. 